\title{
The European Influence on Sikh Portraiture: Representations of Maharaja Ranjit Singh, Sher-e-Punjab (the Lion of the Punjab)
}

\author{
Atsushi lkeda \\ PhD Candidate, History of Art and Archaeology, School of Oriental and African Studies, \\ University of London, United Kingdom. Email: ikedatsushi@gmail.com
}

\begin{abstract}
Maharaja Ranjit Singh was one of the greatest patrons in the early modern period of South Asia. Under his sovereignty, local ateliers like the Imam Bakhsh workshop developed and many European artists like August Schefft and Emily Eden visited the Punjab region. His reign was also the period of economic and social growth, which fostered the spirit of Punjabi cultural identity across the Sikh Kingdom. Representations of Ranjit Singh changed significantly from his lifetime to posthumous portraits; the latter is characterized by advanced pictorial expression rather than the simply realistic technique. More development is evident in the colonial period, when the number of single portraits increased perhaps due to the import of small media like ivory and mica. Portraits of Ranjit Singh represent increasing European influence on Sikh art.
\end{abstract}

Keywords: Sikh art, portraiture, Maharaja Ranjit Singh, early $19^{\text {th }}$ century

\section{Introduction}

Ranjit Singh was one of the greatest patrons in the early modern period of South Asia. It is evident that a Muslim workshop developed under his sovereignty $(1799-1839)$ in the early $19^{\text {th }}$ century (Lafont, 2002; Lafont and Schmitz, 2002). The most famous artist of the atelier was probably Imam Bakhsh for he is described in the inscription of several works as 'Imam Bakhsh Lahori', or Imam Bakhsh living in Lahore (Lafont, 2002). R. P. Srivastava (1980) lists the following families as major families of painters in Lahore in the $19^{\text {th }}$ century: Chughtai, Kehar/Kihar Singh and Purkh-Nainsukh. According to their family trees, a branch of the Chughtai family, Mohd Hayat's clan, used the surname 'Bakhsh' as well as the name 'Imam-ud-din' (Srivastava, 1980). Despite no reference to Imam Bakhsh, it is certain that he belonged to the Bakhsh family and worked as a painter in Lahore.

Lafont and Schmitz (2002) point out that Imam Bakhsh received patronage from many Westerners. For instance, General Court ordered the Memoires, which comprises 1,200 pages in five volumes. The

(C) AesthetixMS 2019. This Open Access article is published under a Creative Commons Attribution Non-Commercial 4.0 International License (http://creativecommons.org/licenses/by-nc/4.0/), which permits non-commercial re-use, distribution, and reproduction in any medium, provided the original work is properly cited. For citation use the DOI. For commercial re-use, please contact editor@chitrolekha.com 
first two books are about Persia, the third is about Afghanistan and the last two volumes are about the Punjab. He commissioned Imam Bakhsh to paint them. The Memoires contains numerous portraits of Sikh royalty and nobles, the tribal population of Peshawar, archaeological activities by the French, etc., and landscapes. In addition, Dr Honigberger commissioned lithographic engravings illustrating his own memoirs, Thirty-Five Years in the East. It comprises mostly 'faithful copies of Portraits and Sketches taken by a native of Lahore.' (Honigberger, 1852, vol. 1, p. 195) General Allard is the most prominent patron of Imam Bakhsh because he commissioned a famous family portrait and an exquisite Fables of La Fontaine, which includes a frontispiece representing Ranjit Singh, icons of French officers and some animal scenes. General Court and Allard requested several times that Imam Bakhsh produce illustrations of Manuel d'infanterie, or the Military Album, which contains images of Ranjit Singh and the Sikh Gurus. In addition to French patronage, a Muslim nobleman became a patron of Imam Bakhsh. 'Abd al-Majid Khan commissioned three masnavis (versenarratives) which bear ten fine miniatures.

Furthermore, it is important to note that Ranjit Singh's patronage prompted Jeevan Ram and Hasnal-din to import oil paints, perhaps in the 1830s. They were attendants of Lord William Bentinck. Kessar states, 'The Panjabi artist became oriented for the first time to the possibilities of capturing visual experiences rather than the prescribed one' (Kessar, 2003, p. 119). There were many European artists in Ranjit Singh's court, such as August Schoefft and Emily Eden, although they were far less in number than local painters in the early $19^{\text {th }}$ century. The following description of European painters refers to Hasan's work in 1998.

August Schoefft (1809-88) was a professional Hungarian painter and renowned for his work in the Sikh courts at Lahore and Amritsar. He arrived in India at the age of 29. He portrayed Nawab of Arcot, Ghulam Muhammad Ghaus, and Ghaus' uncle, Prince Azim Jah, a year later. In Delhi, he painted the last Mughal emperor, Bahadur Shah Zafar, and two of his sons, Mirza Mughal and Mirza Jawan Bakht (Greig, 2008, p. 26). Once he arrived in Lahore in 1841, Maharaja Sher Singh invited him to Amritsar. He arrived in the Punjab in the reign of Maharaja Sher Singh. In less than a year, he completed many huge oil paintings, including Darbar of Maharaja Ranjit Singh at Amrtisar. Schoefft nearly fell victim to violence by radical Sikhs because he smoked near the Golden Temple (Hasan, 1998). The story tells of a typical problem between locals and foreigners, that is to say, a part of colonialism. Schoefft took his drawings to Europe and painted them in Vienna ten years later; they are now composed of the Prince Bamba Collection, Lahore Fort (Greig, 2008, p. 26).

Emily Eden (1797-1869), was an amateur artist and the sister of the Governor General, Lord Auckland. She was a prominent figure among amateur artists and produced many drawings of the people of the Punjab. She came to India with her brother between 1836 and 1842. She visited the region in the winter of 1838 , just a few months before Ranjit's death. Her 193 drawings are now 
located in the Victoria Memorial in Kolkata (Greig, 2008, p. 25). She published Portraits of the Princes and People of India in London in 1844 with the help of the lithographer, J. Dickinson. She is also considered an important artist because of the portraits she painted of Ranjit Singh during his lifetime (Hasan, 1998).

Among Sikh royalty and nobility, Ranjit Singh was the one who was most often depicted in portraiture throughout the $19^{\text {th }}$ century. However, Archer (1966) notes that although the Maharaja provided much patronage to artists in his court, Ranjit Singh did not like painters to portray him. According to Archer, this was due to his unattractive appearance from childhood. Regarding the relationship between Ranjit Singh's death and portraiture, Singh (1981) argues that in the first stage painters must have depicted his face from the right during his lifetime because he had been blind in the left eye since childhood (pp. 95-96). In the second stage, after Ranjit Singh died in 1839, painters gained the freedom to portray him full face. In the third stage, Ranjit Singh came to be rendered with a golden halo (Singh, 1981, pp. 95-96).

Although artists tended to paint Ranjit Singh in profile at first, it is doubtful they minded his blind eye, due to their respect for the subject. Their factual concern seems to have been that the blind eye prevented them from rendering his expression. It has been pointed out that this issue is, in fact, due to his patronage. Ranjit Singh would have commissioned his portraits for the recording purpose. Similarly, the norm of the profile view was less strict in posthumous paintings, but this is likely because of the Western influence. Furthermore, a halo was a common feature in this period and is found in the previous phase as well, albeit less vividly. In addition, European artists also portrayed Ranjit Singh, but there has not been a complete study of their works. Finally, portraits of other famous Sikhs, painted by both local and European artists, were significantly marginalised in previous studies.

Thus, this paper explores how the circulation of European ideas, aesthetics and visual culture impacted upon Sikh-Punjabi artists and patrons throughout the 19th century. To do this, I examine portraiture of Maharaja Ranjit Singh as a representative of Sikh royalty and nobility in terms of the Western influence on production and consumption of the art. All of his portraits in this paper were created in Lahore between 1799 and 1900, which present differing views of how Sikhs were presented. The analysis focuses on the subject's age, style of painting and painter's style. The works are listed in chronological order. This paper comprises three sections: the Sikh Kingdom of Lahore; early portraits of Ranjit Singh; and colonial portraits of Ranjit Singh. 
4 | The Chitrolekha Journal, Vol. 3, No. 1, 2019, Section 1

\section{The Sikh Kingdom of Lahore}

The evolution of Sikh power is the most remarkable occurrence in the political history of the Punjab region of the $18^{\text {th }}$ and $19^{\text {th }}$ centuries. After Guru Gobind Singh died in 1708, Banda Singh (1670-1716) started an initiative for Sikh self-governance. The Khalsa, Gobind's followers, came to be classified into twelve divisions, or Misls. Their succession was basically republic, but sometimes hereditary (Cole and Sambhi, 1978, p. 162). Among them, the Sukerchakia misl inaugurated 18-year-old Ranjit Singh as their head. He was to become the most renowned as Sher-e-Punjab, or the lion of the Punjab.

In 1799, Ranjit Singh unified the twelve misls into one state, or Sarkar-i-Khalsa, and gained control of Lahore, the second capital of the Mughal Empire. Ranjit Singh proclaimed the Court of Lahore and designated himself Maharaja in 1801. Therefore, his kingdom is also known as the Sikh Empire or the Empire of the Sikhs. In almost forty years, Ranjit Singh conquered Afghan territories to the west, Kashmir to the north and Lhasa and Tibet to the east. Following the 1830 , his reorganised the Sikh military in the western manner by recruiting Napoleon's subordinates, such as Jean-Francois Allard and Jean-Baptiste Ventura. Partly because of the 1809 Sikh-British treaty that set the Sutlej as the military border between them, Ranjit's modernised army defended their land from the East Indian Company until the Maharaja died in 1839.

Ranjit Singh appointed governors (nazims) to rule his territories and developed centralised administrative power, which included the entire record of income and expenditure of the state (Grewal, 1990, pp. 109-113). He introduced cash salaries for his court ministers and army generals. However, jagirs, or feudal land grants, often free from taxation, were still the most important mode of payment in the state. Some jagirs were bequeathed to descendants if they made an outstanding contribution to the state. This was particularly the case in religious lands. Another economic trait of Ranjit Singh's reign was the revival of cultivation and trade, which were supported in part by the grant of revenue-free lands. Ranjit Singh launched state loans to dig new wells. Such state policy underpinned the cultivation and irrigation of land. This was followed by an increase in manufacturing based on family business such as the Kashmir shawl industry; the exception was salt production, which was monopolised by the state. Trade of agricultural, manufactured and natural products flourished under strong public security and the development of a traffic network (Grewal, 1990, pp. 109-113).

In the Sikh Kingdom, all the ethnicities, such as Hindu, Muslim and Sikh, were treated as equal. For instance, Ranjit Singh promoted people on the basis of their ability, not their religion. Moreover, Persian was adapted as an administrative language and was also as important in scholarship as Sanskrit, whereas the Punjabi language and Gurmukhi script became more widely accepted as a 
common ground. As a result, the regional identity of the people was gradually formed (Grewal 1990, 113-119).

Nevertheless, Sikhs occupied more than $50 \%$ of the ruling class. The royal family were exclusively a Sikh and all commanders of the army were the Khalsa. It is evident that a distinction between the Keshdharis and the Sehajdharis existed in the early $19^{\text {th }}$ century, apart from minor sects such as the Akalis and the Nihangs. Although there was enough social differentiation in the community, it is certain that they are now governed by their own people. In many ways, the ideas of equality, the need for mobility, and the requirements of guerrilla warfare allowed the Khalsa creeds to match the milieu of the $18^{\text {th }}$ and $19^{\text {th }}$ centuries (Singh, 2000, p. 82).

Ranjit Singh's kingdom came to its end due to weak successors, royal rivalry and British intrigue. After Ranjit Singh died in 1839, the Sikh Kingdom fell into succession conflicts among the royalty and nobility at the Lahore Court. Only three were enthroned: Kharak Singh, Nao Nihal Singh and Duleep Singh. Other important characters were the Hindu Dogra brothers, the Attariwala and Sandanwalia families and Maharani Jindan, who acted as guardian of young Kharak Singh. Afghan Muslim rulers also played a pivotal role during the last period, as they fought with the British even after the Sikhs were defeated. The Treaty of Lahore (1846) and the subsequent annexation of Punjab by the British (1849) brought about the de facto end of the Sikh state (Singh, 2000, p. 82).

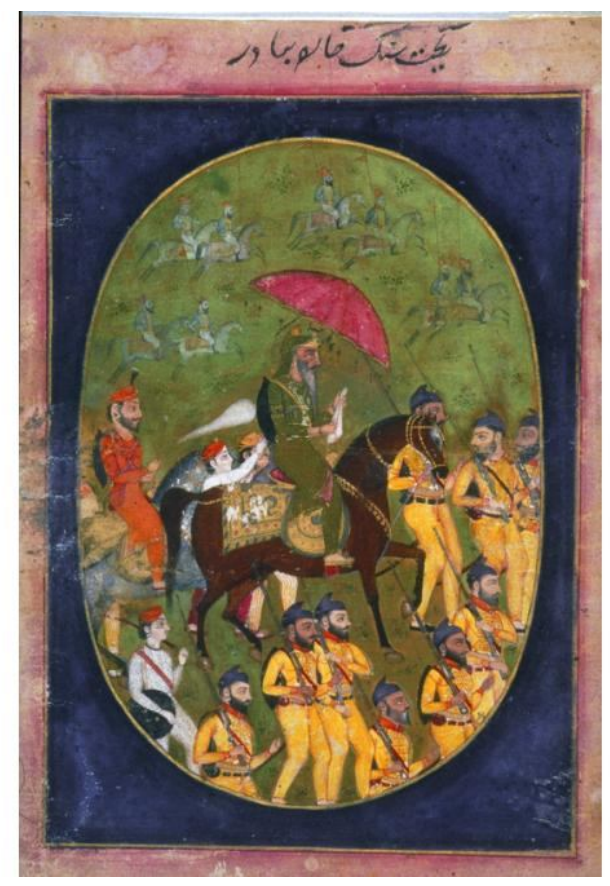

Figure 1: Maharaja Ranjit Singh on horseback. Punjab. Ca.1830-1839. Opaque watercolors on paper. 16.5(19.05)×11.4(14.6) cm. Acc.no.1998.98, Asian Art Museum, San Francisco. 


\section{Early Portraits of Ranjit Singh}

One of the earliest portraits of Maharaja Ranjit Singh is Maharaja Ranjit Singh on horseback (Figure 1). Although the artist is unknown, Lafont (2002) attributes this painting to exactly 1830 (p. 130). We have no evidence to prove his chronology, but Ranjit Singh in this picture has partially a black beard which may imply its year of execution. All figures in this painting facing right in profile wear an orange cloth and headgear. The same coloured saddle flap is equipped with a white horse decorated by many accessories. Ranjit Singh on it carries a bow, arrows and shield on the back. His right hand grasps reins, while his left hand picks something. A soldier holds a red canopy for Maharaja. The horse raises his forelegs and is seemingly rushing although we have no impression of mobility in this painting. The horse`s attitude probably expresses Ranjit Singh`s bravery to have conquest large areas of Punjab, Kashmir and Afghanistan. A solider leads Ranjit Singh and the horse, and then four soldiers follow Maharaja. A horizon is very high and there are some trees in distance.

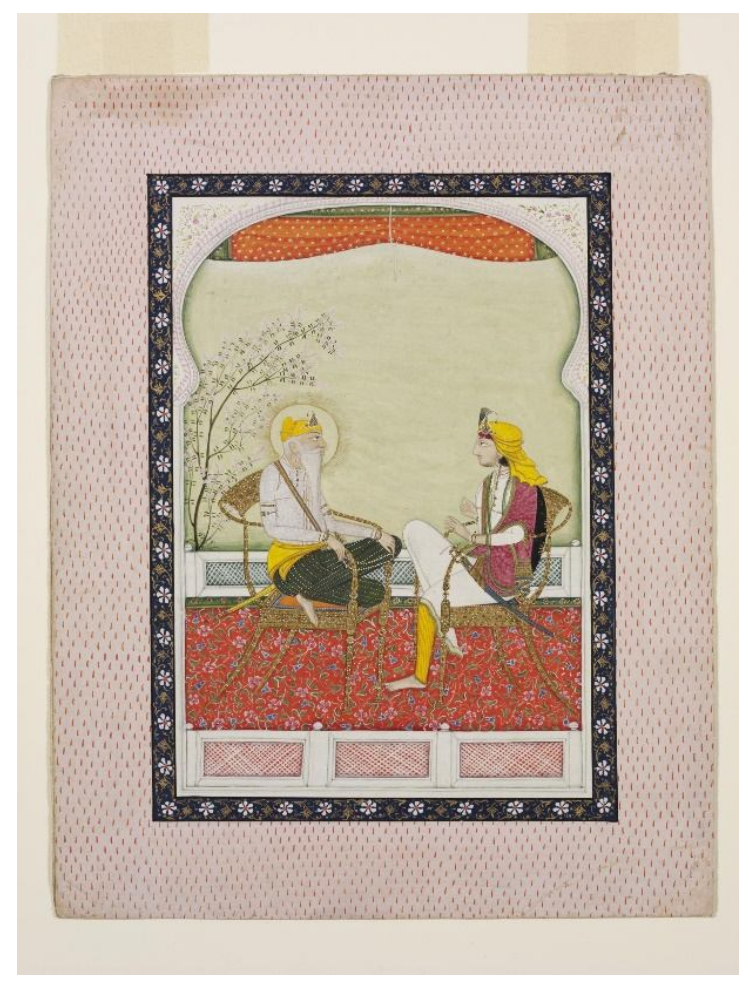

Figure 2: Ranjit Singh and Hira Singh. Artist unknown. Punjab. Ca.1838-1840. Opaque watercolour and gold on paper. 20.1(28.3)×13.9(22.2) cm. Acc.no.IS.114-1953, Victoria and Albert Museum.

There is another equestrian portrait of the similar composition (Figure 2). Ranjit Singh on horseback shows Maharaja holding a grey beard, but he has a handkerchief rather than a bow and arrows. The inscription says "Bahadur Ranjit Singh". The oval format is another different aspect of this second equestrian portrait. The space is narrower, but more soldiers and servants are painted within the 
frame. Ranjit Singh wears a green cloth and headgear under a crimson parasol raised up by an attendant. Everyone except a soldier faces right in profile. Soldiers bear a pistol rather than a sword. This fact reminds us of Ranjit Singh having introduced French military culture into his army. A horse below Maharaja walks slowly rather than rushes. One noble dressed in an orange cloth and held a shield on the back follows Ranjit Singh with his horse. Others run around the field in the background. Yellow clothes of soldiers glow in the green field and blue frame.

Likewise, there is a double portrait of Ranjit Singh and a Sikh noble man which holds similar coloured frame to many of contemporary works (Figure 3). The format is a combination between oval and square. Ranjit Singh sits on the European chair with his legs folding on it under the blossoms. He wears a yellow headgear and his head is surrounded by a halo. The counterpart also sits on the European chair, but his legs are down to the ground and cross each other. He wears a yellow headgear and a crimson gown, and then holds a sword on the waist. The carpet is decorated in floral pattern and the similar colour is used in a curtain rolled up at the top. Intriguingly, five portraits of the similar borders are owned by the same museum. Archer attributes four of them to c.1838-40, but I think that the year of their production is earlier than Archer's view.

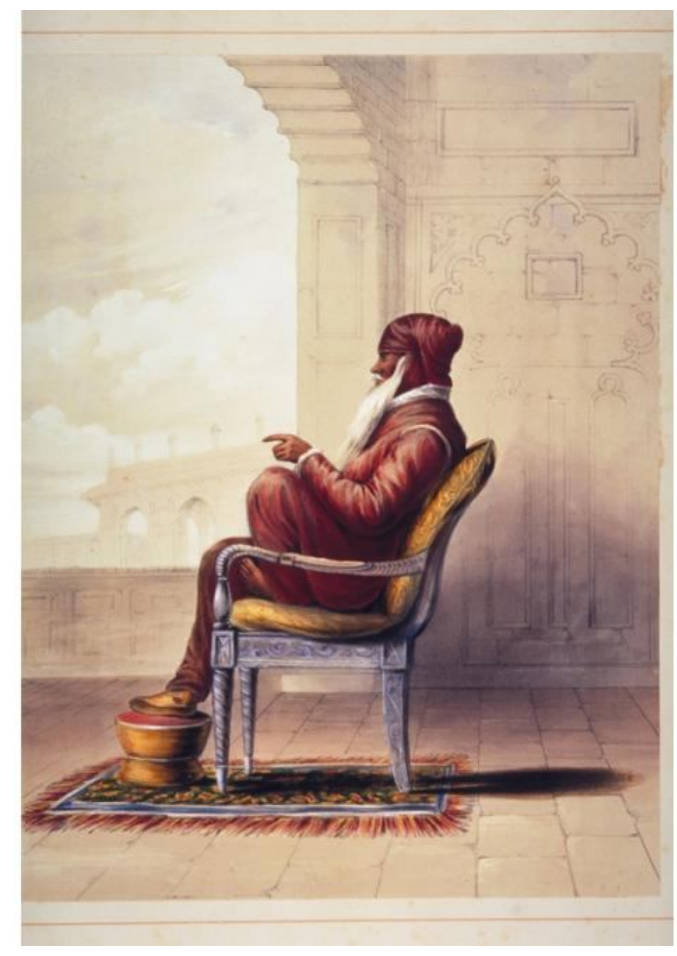

Figure 3: The Late Maha Raja Runjeet Singh. Drawn by Emily Eden, Painted by L. Dickinson, Published by L. Dickinson and Son. Portraits of the Princes and People of India. approx. 1838-1843. 61×44.4cm. Chromolithograph. Acc. no. 1998.63.13, Asian Art Museum, San Francisco. 
This painting is a copy of original drawing by Emily Eden (Figure 4). In Amritsar, Ranjit Singh received Lord Auckland and Emily Eden at the Rambagh Palace. Maharaja was already sick when they arrived there. The painting was made in Lahore in 1838. Lafont (2002) argues that this is the last portrait of Ranjit Singh (p. 169). In this portrait, He is sitting on the European chair and using a footrest, which are put on the well-designed carpet. He faces left in profile and is pointing something by his left hand. His beard is completely white and he is wearing red headgear and cloth. The background is divided to two sections: the right is a wall of indoor and the left side is a landscape which shows a roof of another building.

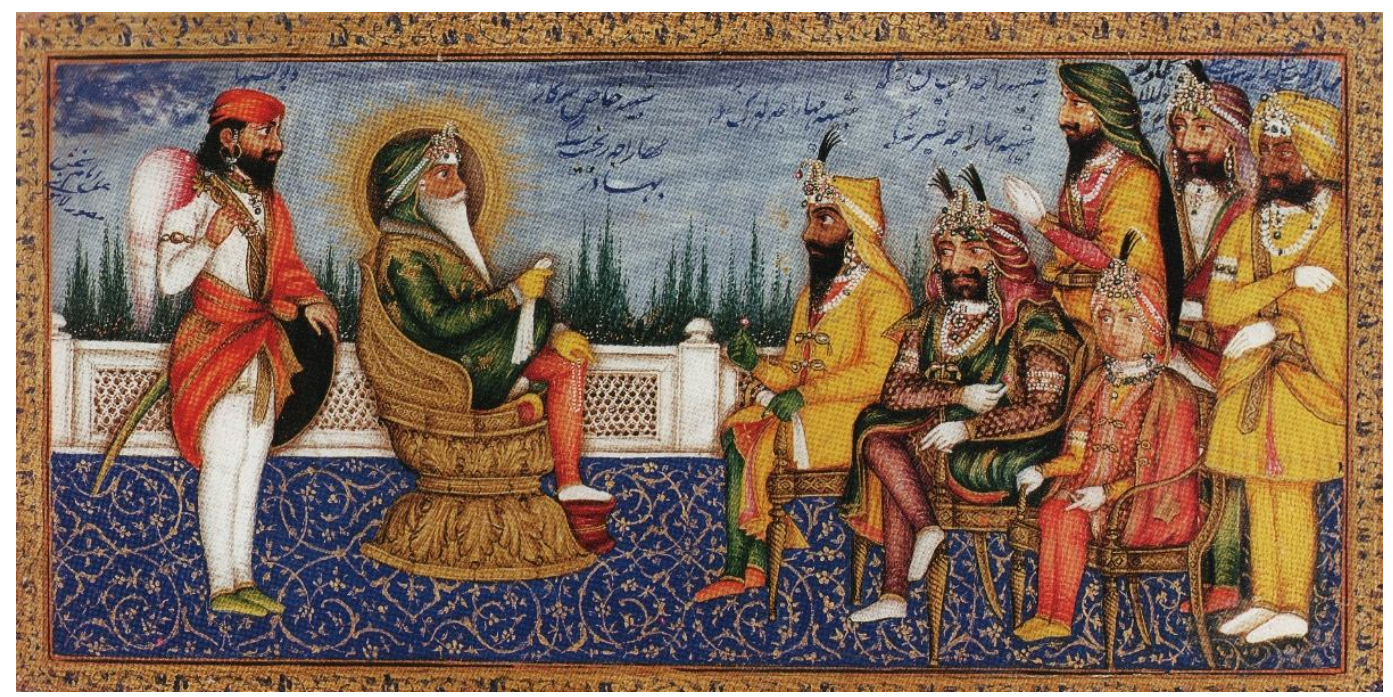

Figure 4: Maharaja Ranjit Singh in Darbar. Singed by Imam Bakhsh. Lahore. Gouache on paper. 30.9×18.2 cm. Acc.no.3722, Government Museum and Art Gallery, Chandigarh.

The next portrait, Ranjit Singh at Darbar, is signed by Imam Bakhsh Lahori (Figure 5). This painting is unusually a long oblong format. On the left hand side, Ranjit Singh is rendered with his armed attendant holding a feather fan, a sword and a shield. He is represented as an elderly having a white beard. His head is circled by a halo in which the inner space is black, and the edge releases rays in all directions. Maharaja faces right in profile and is sitting on the traditional chair coloured in gold. He is wearing a green attire and headgear, and a red trouser, holding a white handkerchief in the right hand and a rosary on the left hand. His right leg is folded on the chair and his left leg is put on the footrest. On the right hand side, the six famous royalty and nobles of Lahore court such as Kharak Singh, Sher Singh and Dalip Singh were depicted being indicated with a Persian inscription. Three in the front row were sitting an European chair and the rest of three of the back are standing. The floor is beautifully decorated by an arabesque and the lattice works are shown underneath the green trees in the back ground. 


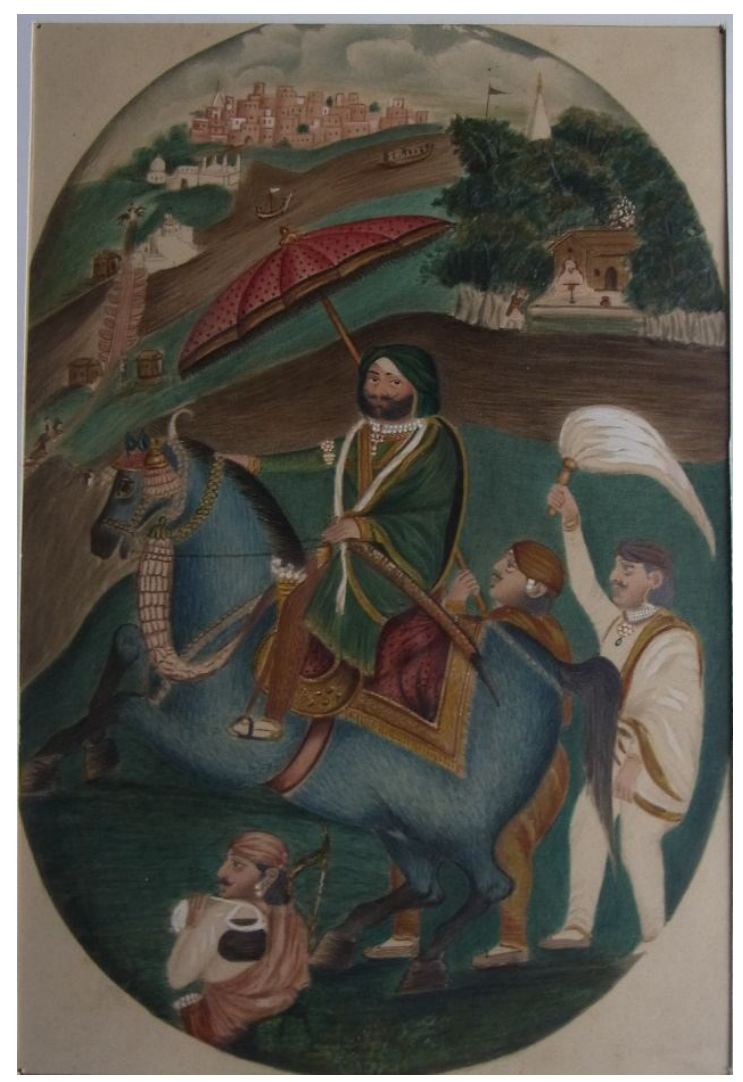

Figure 5: Ranjit Singh Heading to the Lahore Castle. Possibly by Imam Bakhsh. Lahore. 2rd quarter 19th century. The Punjab Archives, Lahore.

One of the most contentious portraits is Ranjit Singh heading to the Lahore Castle (Figure 5). This portrait has long been known as a Sikh guru by its owner. However, I will argue that this is certainly a portrait of Ranjit Singh and possibly executed by Imam Bakhsh workshop. Although I agree that there are some deviations from Ranjit Singh common iconography, no Sikh guru is represented in this way. Only three quarter face reminds us of the depiction of Guru Nanak, but we have already known that Ranjit Singh was depicted in three quarter face and sometimes as young age after his death. My opinion could be the process of elimination, but it is not impossible to regard the figure as Great Maharaja. Ranjit Singh holding a completely black beard rides on the blue horse which raises his forelegs. He who wears a green court and hood looks at us in three quarter view. There are three servants within an oval frame. A servant raises a red parasol on his head. Another attendant holds a peacock-feather fan, while the third attendant with a bow and arrows stands at the bottom. The background is more various than any precedent works. On the left side, a castle and city lie beyond a river as if the scene was painted from life. Some ships are floating on the river and some people cross over the bridge. On the right side, we can see an ascetic in the hermitage in the forest. This scene invokes the episode that Nanak had dialogues with different saints in his journey to Baghdad. This idea of mixture between the image of Guru Nanak and that of Ranjit Singh may be derived from the 
coinage of that time that provides the dominancy of Guru Nanak and Gobind Singh in Sikhism (Mann, 2004, 51-54). Sky is overlapped by white clouds. This portrait should be of importance, but it is difficult to identify when it was depicted and why the painter created such an ambiguous image. Just Jenkins mentions that Kings were sometimes deified in sixteenth century Europe (Jenkins, 1947). It could be common expression in state portraiture of any kinds of culture, although exactly speaking, Guru Nanak is not a deity but a founder of religious sect.

\section{Colonial Portraits of Ranjit Singh}

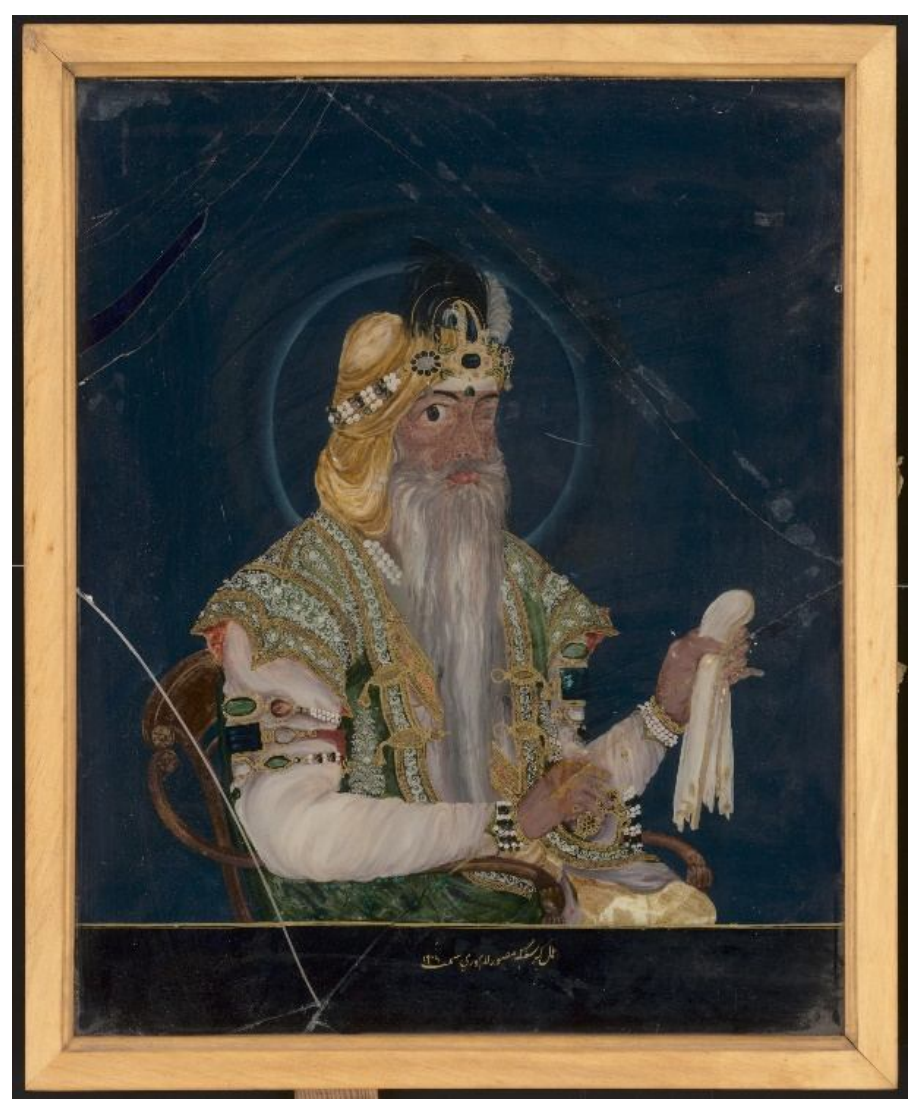

Figure 6: Portrait of Maharaja Ranjit Singh, Nimbate. By Kehar Singh. Lahore. Ca.1849. Gouche on Glass. $50.8 \times 40.6 \mathrm{~cm}$. Acc.no.03530(IS), Victoria and Albert Museum.

As the first painting, Maharaja Ranjit Singh by Keher Singh should be listed because the inscription says that this portrait was produced by him in Lahore in C.1849 (Figure 7) (Archer, 1992, 191). This could be in the category of the former period, but the style and impression are very new in the history of portrait. The first reason is that the portrait was painted on the glass, which enables the realistic and naturalistic presence of Maharaja. The second reason is that the work is the first bust portrait in my archive. Ranjit Singh faces left or front in three quarter face. His left eye is looking at 
audience. He is sitting on the European chair and holds a handkerchief in his left hand. His right hand is being put on the hilt of a sword. He wears a golden headgear with a black feather and a green gown with a lot of jewelry. His white beard is realistically mix up with a grey one. His head is circled by a weak but clear nimbus. This portrait is unusual achievement by a renowned artist, Kehar Singh, and show the arrival of a new era in colonial circumstances.

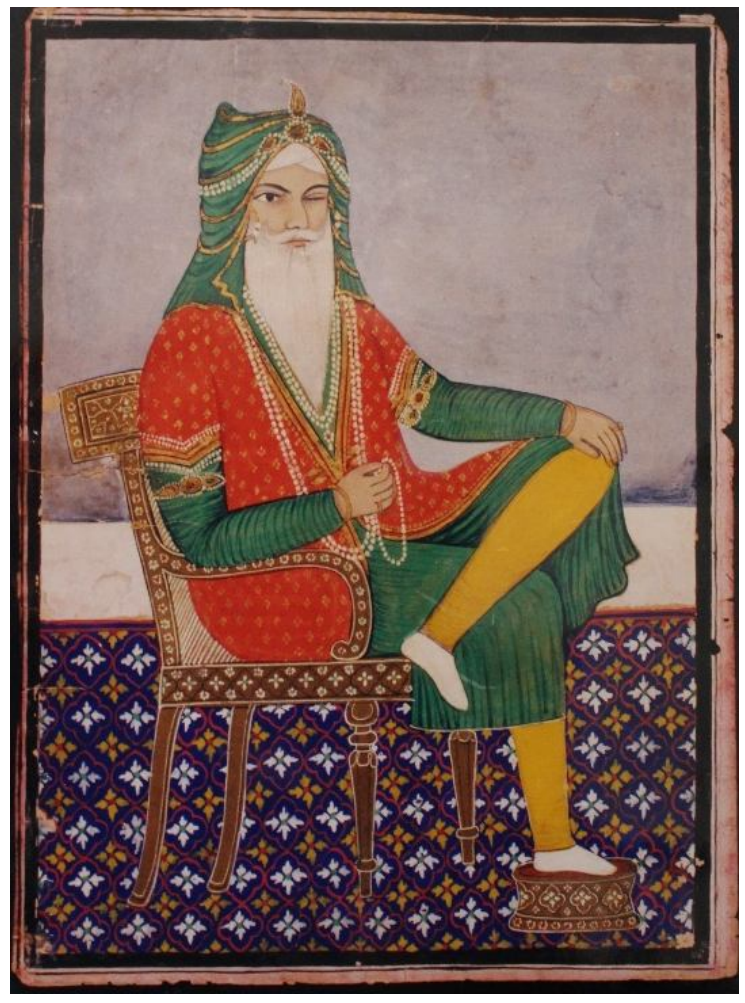

Figure 7: Maharaja Ranjit Singh. Artist unknown. Punjab. Ca.19th century. Watercolor on paper. 13 5/8×10 11. Acc.no.2386, Government Museum and Art Gallery Chandigarh.

Again, we can see the familiar iconography of Ranjit Singh (Figure 7). Maharaja Ranjit Singh on the chair shows his sitting on the European chair. He faces right in three quarter face. He is wearing a green headgear and cloth under a red jacket. His trouser is painted in yellow. Ranjit Singh holds a necklace in his right hand and his left hand is being put on the knee. He is using a footrest for his right leg and his left leg is folded on the chair. The carpet is decorated by stylistic flowers without any shortening. There is no sky in the background, but small trees are shown on the edge of terrace. This is a single portrait and implies the new western influence from the British Empire. 


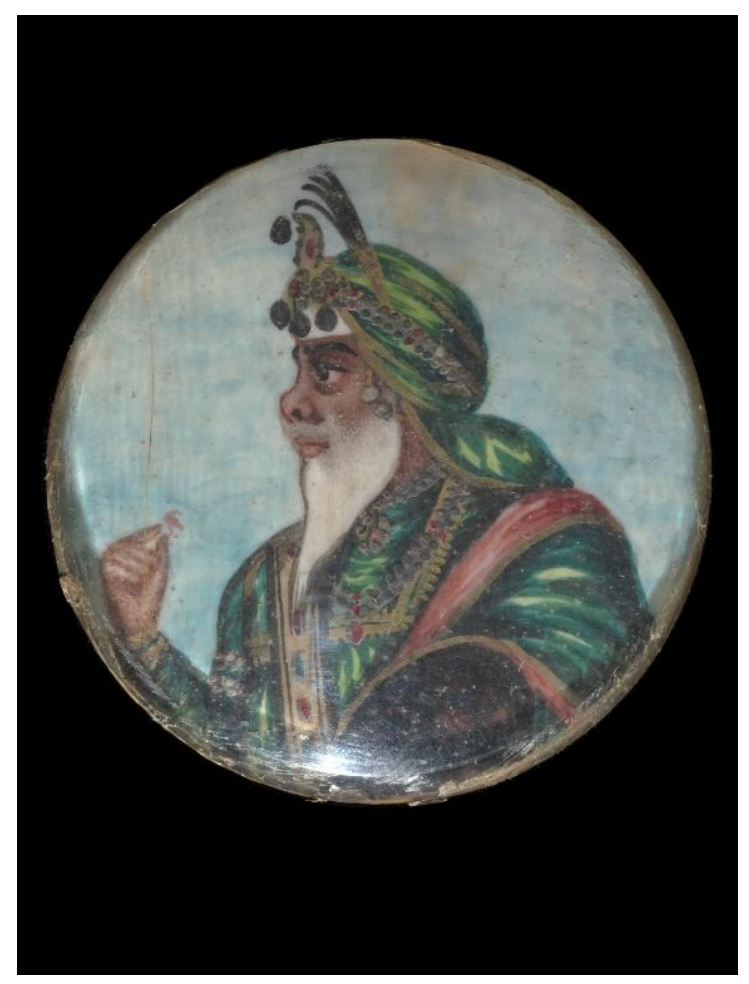

Figure 8: Maharaja Ranjit Singh. Artist unknown. Lahore. Ca.1850-ca.1870. Painted on ivory. Acc.no.IS.167-1954, Victoria and Albert Museum.

One of new elements of this phase is an introduction of many ivory paintings (Figure 8). One of fourteen ivory painting shows Ranjit Singh facing left in profile in a bust portrait. The supporter is cut roundly. Maharaja is wearing a green headgear and dress. He is holding a flower between his thumb and finger. Also, it seems that he has a black shield by his left hand. His beard is painted completely in white. His face is portrayed very realistic and, in particular, the depiction of his nose is sophisticated; its bridge line is exquisite and its swelling is naturally rendered through some shading. However, this portrait has a contradiction or error in his iconography. Ranjit Singh is known as his left eye being blind and covered by an eyepatch. The image does not follow such an actual appearance. Although Victoria and Albert Museum illustrates this portrait as Company Painting from Lahore, it may include some factual error. If this is a Company painting or made by an Indian local artist, he seems to have lived outside Lahore such as Delhi. If this was produced in Lahore, the artist is not local but alien i.e. British. Otherwise, Lahore local painter may delete Ranjit Singh's eyepatch deliberately for the aesthetic reason. If so, this 'imaginary' portrait shows a new attempt unprecedented in the early $19^{\text {th }}$ century. 


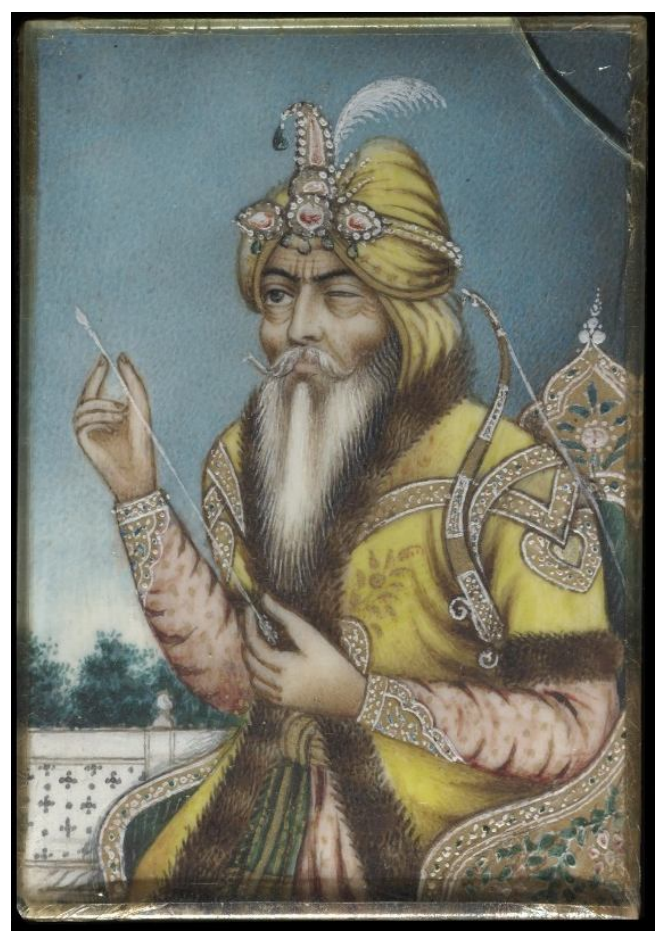

Figure 9: One of Two Portraits of Maharaja Ranjit Singh (1780-1839). Artist unknown. Delhi. Ca. 1900. 6.5×3 cm. Watercolour on ivory. Acc.no. IS.524-1950, Victoria and Albert Museum.

In this painting (Figure 9), Ranjit Singh who has a white beard and faces left in three quarter view is sitting on a European chair that is finely decorated with colourful stones and has a floral design on the top. He is wearing a yellow turban attached with a white feather and a sort of crown decorated with colourful stones. He is also wearing a yellow jacket in which edges are attached with brown furs. His inner dress is painted in yellow with dots and its sleeves are decorated with floral patterns. He is holding a stick in both hands and a silver-and-brown bowis hung from his left shoulder. On the bottom left, the white lattice works are rendered under which a green trees are depicted. The background is gradually painted in blue towards the top. 


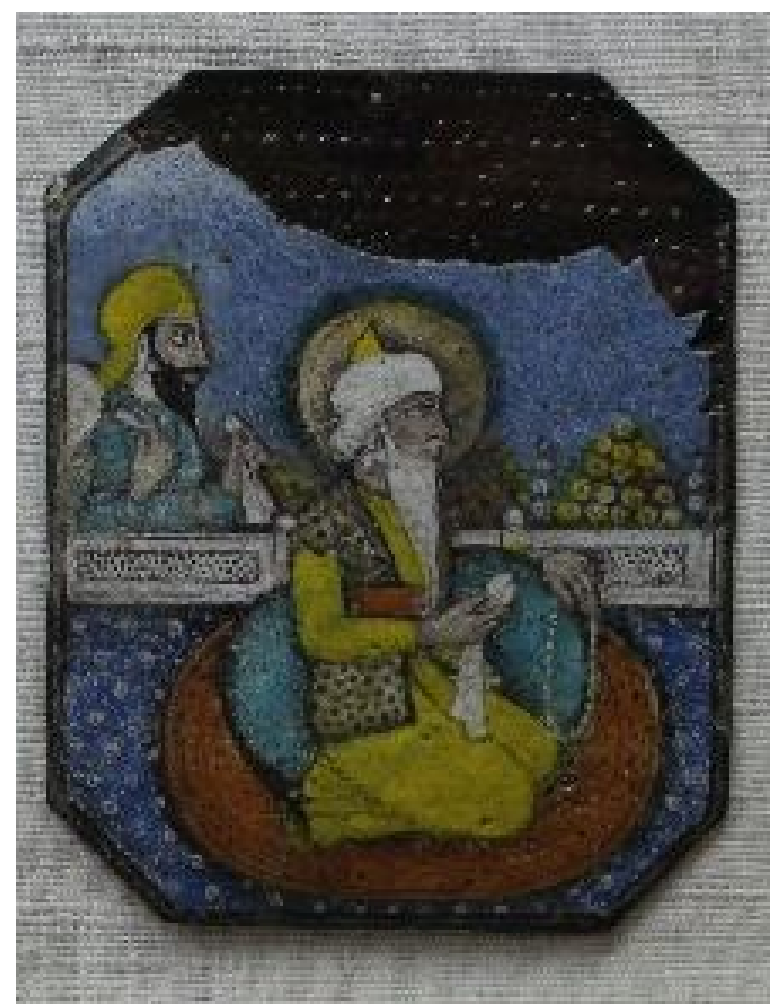

Figure 10: Maharaja Ranjit Singh. Artist unknown. Punjab. ca. 1900. 10.3×8.2 cm. Painted metal with meena work. Acc.no. 96.198, National Museum, New Delhi.

In this painting (Figure 10), Ranjit Singh who has a white beard and faces right in profile is sitting with his legs folded on a red cushion. His head is encircled with a halo painted in gold in which the border is shadowed. He is wearing a yellow turban tied with a white bandana as well as a yellow dress under a golden jacket with black dots. He is leaning against a green pillow while holding a white handkerchief in his left hand and a white rosary in his right hand. The floor carpet is painted in blue and decorated with floral patterns. Beyond the white lattice works, an attendant who has a black beard and faces right in profile is standing on the left hand side. He is wearing a yellow turban and a blue dress while holding a white fly whisk in his right hand and a white handkerchief in his left hand. Green trees with a lot of colourful flowers are rendered. The background is painted in blue.

\section{Conclusion}

Although Ranjit Singh was painted in the realistic Mughal style as a powerful and elderly ruler during his lifetime, his head was often encircled by a halo representing the dignity and holiness of the Mughal emperors. If a halo was painted, it was half-transparent or used the same colour as the background. The realistic attitude of his court painters was linked inextricably to the predominance of portraiture in painting. However, most of the works created by local painters were not portraits of 
individuals. Ranjit Singh was always surrounded by one or more figures, such as attendants and soldiers. If there was courtly scenery, many famous figures were painted around him, paying homage and talking to the Maharaja.

Ranjit Singh died at the age of 55 in 1839. His posthumous images were painted between 1840 and 1849 (this was the year the Sikh Kingdom came to an end). The paintings were created in an idealistic but technical manner, which included plump modelling and the use of highlighting, derived from Western painting. The distinctive style can be considered to be the foundation of the Lahore School. Other characteristics are that Ranjit Singh was exhibited as a youth once upon a time, and that the compositions tended to include more people than those painted during his lifetime. In other words, posthumous images of Ranjit Singh were contextualised into scenes of celebration, in which many courtiers were identified by their attributes and inscriptions. In comparison with the former simple depictions, the pictorial expression of the Maharaja advanced after his death.

In the late $19^{\text {th }}$ century, Ranjit Singh tends to be depicted in a single portrait. His image is likely to be a bust often in so-called the jhatka window stemming from Mughal portraiture. The tendency of a profile disappears and a three quarter or even a frontal view is dominant in his face. Only some portraits which seemingly depend on the earlier iconography shows a strict profile. The medium is varied from lithograph to oil and from mica (metal or glass) via lithograph to ivory, which leads different styles from the folk-like to the realistic. Perhaps, the new media were related to an increase of a single portrait because they were smaller in size than both traditional miniatures and European painting.

\section{References}

Archer, Mildred. (1992). Company Painting: Indian Painting of the British Period. London: Victoria and Albert Museum

Archer, William George. (1966). Paintings of the Sikhs. London: Her Majesty`s Stationary Office

Cole, W. Owen, and Sambhi, Piara Sing. (1978). The Sikhs: Their Religious Beliefs and Practices. London: Routledge \& Kegan Paul.

Greig, Charles. (2008). 'Artists from Afar: Company Painters in the Princely Courts of India 1770-1900.' Portraits in Princely India. Marg Vol. 59, No. 4, 16-29. Mumbai: Marg Publication

Grewal, J.S. (1990). The Sikhs of Punjab. Cambridge: Cambridge University Press.

Hassan, Musarrat. (1998). Painting in the Punjab Plains. Lahore: Ferozsons (Pvt.) Ltd. 
Jenkins, Marianna. (1947). The State Portrait: Its Origin and Evolution. New York: College Art Association America.

Kessar, Urmi. (2003). Twentieth-century Sikh painting: the presence of the past. New Insights into Sikh Art. edited by Kavita Singh. Marg Publication

Lafont, Jean-Marie. (2002). Maharaja Ranjit Singh: lord of the five rivers. Patiala: Punjabi University

Lafont, Jean-Marie and Schmitz, Barbara. (2002). After the Great Mughals: Painting in Dehli and the Regional Courts in the $18^{\text {th }}$ and $19^{\text {th }}$ centuries. Mumbai: Marg Publications. vol53 no. 4

Mann, Gurinder Singh. (2004). Sikhism. London: Laurence King Publishing Ltd

Singh, Man Mohan. (1981). "Changing Faces of Maharaja Ranjit Singh in Portraiture”. Maharaja Ranjit Singh as Patron of the Arts, edited by Anand, Mulk Raj. Bombay: Marg Publications. 95-108

Singh, Gurharpal. (2000). Ethnic Conflict in India: A Case Study of Punjab. Basingstoke: Macmillan

Srivastava, R.P. (1983). Punjab Painting: Study in Art and Culture. New Delhi: Abhinav Publications

Atsushi Ikeda is a Japanese historian of South Asian art and visual culture, particularly Sikh painting from the early modern period. He has recently been enrolled at the doctoral degree at the School of Oriental and African Studies, University of London. His thesis has explored the colonial transformation of Sikh identity with a special focus on portraits of Guru Nanak, the founder of Sikhism. His current interest lies in life and work of Sobha Singh known as a portraitist of the Sikh Gurus with reference to Khalistan Movement, the Sikh independent movement. 